\title{
Sexual function in women with advanced multiple sclerosis
}

\author{
Birgitta M Hulter, Per Olov Lundberg
}

\begin{abstract}
Changes in sexual function in 47 women with advanced multiple sclerosis are described. Twenty eight (59.6\%) of the women reported decreased sexual desire. Seventeen $(36 \cdot 2 \%)$ reported decreased lubrication. Five $(10 \cdot 6 \%)$ others did not know if they lubricated or not. Eighteen women $(38 \cdot 3 \%)$ reported diminished orgasmic capacity and six $(12 \cdot 8 \%)$ others had never had an orgasm. Sensory dysfunction in the genital area was experienced by $61 \cdot 7 \%$ of the women and $76 \cdot 6 \%$ had weakness of the pelvic muscles. Sixty six per cent had bowel problems and $89.4 \%$ had bladder dysfunction. The changes in sexual function correlated both with neurological symptoms from the sacral segments, such as weakness of the pelvic floor and bladder and bowel dysfunction, and to other symptoms such as ataxia and vertigo as well as with age and the occurrence of amenorrhoea. A significant correlation was found between expanded disability status scale (EDSS) score and cohabitation. Problems with sexual function were reported significantly more often by women with lower EDSS scores. Most women (83\%) found the interview a positive experience.
\end{abstract}

(F Neurol Neurosurg Psychiatry 1995;59:83-86)

Keywords: multiple sclerosis; female sexuality; sexual dysfunction

Symptoms of sexual dysfunction are very common among patients with neurological disorders, particularly myelopathies and polyneuropathies. ${ }^{12}$ Almost all patients in advanced phases of multiple sclerosis have changes in their sexual life..$^{3-7}$ Even in early and mild cases, sexual dysfunction is common. ${ }^{8-9}$ It may be the presenting symptom. The purpose of the present investigation was to determine to what extent women with multiple sclerosis had experienced changes in their sexual lives and whether the changes could be correlated to neurological symptoms and handicap score.

\section{Patients and methods}

Fifty seven women with definite or probable multiple sclerosis treated during the period October 1989 to June 1991 were asked to participate in an interview study. The diagnosis should have been known by the woman for at least one year before this investigation. Patients over 60 were excluded. Forty seven women $(82.5 \%)$ aged 21 to 55 (median 46 ) years agreed to take part.

The interviews included social, medical, and detailed sexological case histories. They were structured and followed a protocol that was decided on for this particular study. A separate sheet with answer options was given to the interviewed patient. There was always an open alternative to the specified ones if this was most suitable for the patient. The neurological impairment in each patient was rated from an expanded disability status scale (EDSS). ${ }^{10}$

\section{Results}

SYMPTOMS OF MULTIPLE SCLEROSIS

In $29(62 \%)$ of the patients the first clinical symptom indicating a neurological disorder appeared at the age of 20 to 29 years. The median age at onset of the disease was 26 (range 15-44) years. The median duration of the disease at the time of the interview was 16.5 (range $2-36$ ) years. Ten $(21.3 \%)$ of the women had never experienced any distinct remissions or relapses of the disease. At the time of the interview $76.6 \%$ were experiencing weakness of the pelvic muscles and $61 \cdot 7 \%$ complained of sensory dysfunction in the genital area. As many as $89.4 \%$ of the women had bladder disorders and $66 \%$ had bowel problems.

\section{DISABILITIES}

The EDSS score in the whole group ranged from 1 to 9 (median 6.5). Only three scored $1-2,22$ scored 4-6.5, and 22 scored 7-9. The patients were divided into two EDSS groups, those not restricted to wheelchairs (scores of 1-6.5) and those restricted to wheelchairs (scores of 7-9).

DEMOGRAPHIC FINDINGS

At the time of the interview 24 women were married, 11 had never been married, nine were divorced, and three were widows. 
Twenty nine $(61 \cdot 7 \%)$ were cohabiting with a sexual partner and $18(38.3 \%)$ were not. Of those who experienced separations, 15 in all, $10(66.7 \%)$ said the disease was an important reason for the separation. Eleven of the women did not have children. Thirty six women had one to four (mean $2 \cdot 1$ ) children.

At the time of the interview $76 \%$ of the women in the lower EDSS score group and $45.5 \%$ in the higher EDSS score group were cohabiting with a male sexual partner $(p<$ $0.05)$. Of the 22 women with a higher score eight had separated from a steady or cohabiting sexual partner, and all claimed that this was related to problems emanating from the disease, compared with two of the seven separations $(28.6 \%)$ among the 25 women in the lower EDSS group ( $p<0.05)$.

\section{SEXOLOGICAL FINDINGS}

All women were asked the complete list of intimate questions concerning sexual experiences. The women who had had neither orgasms nor sexual intercourse during the past year, however, clearly had difficulties in judging quality aspects of their experiences. One woman did not wish to answer questions concerning early sexual experiences and orgasms. Two women declined to answer some questions about their masturbation habits. The median number of sexual partners was five (mode one, range one to 50). The women had had steady sexual relationships for a median of 20 (range 0-34) years.

Twenty eight women had experienced a diminished sexual desire for a mean of three (SD 3.4) years (median two, range one month to 14 years). Two other women had experienced a short lasting decrease in libido during the course of the disease. Five women had experienced a stronger sexual desire. Seventeen women were experiencing a delay and some decrease in lubrication. These changes were associated with a deterioration of the disease, with loss of menstruation, and in one case with surgery to create a urostomy. Three further women had noticed a temporary decrease in lubrication, one of them during treatment with the drug emepronium and one during treatment with intravaginal electrostimulation for urinary incontinence. Sexual desire was correlated with lubrication $(p<0.05)$ and lubrication with orgasmic capacity $(p<0.001)$. Of the $30(63.8 \%)$ women who had ever noticed clitoral erections during sexual stimulation, six $(20 \%)$ had experienced a loss of such erections. Seventeen $(36 \cdot 2 \%)$ women had never noticed any clitoral erections.

At the time of the interview the orgasmic capacity had deteriorated in 18 women. Three further women had experienced a temporary decrease in orgasmic capacity. An orgasmic improvement was noticed by three women. In one of them the orgasms were more easily triggered, enabling her to have more orgasms. The sensations were, however, less pronounced. Twelve of the women $(26.1 \%)$ had experienced at least one orgasm within the previous week, 15 women $(32 \cdot 6 \%)$ within the past year. Thirteen women $(28.3 \%)$ had not had any orgasms in the last year and six women (13\%) had never had an orgasm. In 10 women the orgasmic sensations were reduced. They were more short lasting, less intense, or less agreeable. In five women these sensations were intensifiedthat is, they had become longer lasting, stronger, or more pleasant. In these women a good orgasmic quality was significantly $(\mathrm{p}<$ 0.05 ) correlated with non-smoking, with noticed erections of the clitoris, with unchanged erections of the clitoris, and with the subjective feeling of having an attractive body.

Symptoms of weakness of the pelvic floor as well as bladder and bowel dysfunction correlated with changes in lubrication and in orgasmic capacity $(p<0 \cdot 01)$. Sensory symptoms from the trunk and genitals correlated with orgasmic quality $(p<0.05)$. Vertigo correlated with changes in desire, lubrication, and both orgasmic capacity and orgasmic sensation $(p<0.01)$.

When masturbation during the past month was compared with that a month before the start of the disease, one woman reported more frequent masturbation during the past month, and 20 women (43.5\%) less frequent. In seven women there were no changes, and 18 women had never masturbated regularly. During the past month $19(41 \cdot 3 \%)$ of the women had had no sexual intercourse. Fourteen women $(30.4 \%)$ had had sexual intercourse once or twice and 13 women $(28.3 \%)$ three to 10 times (mean number of occasions $2 \cdot 1$ (SD 2.8) median one, range 0 to 10). One woman could not answer. Regarding the frequency of sexual intercourse during the past month compared with that a month before the onset of the illness, two women stated that it had been more frequent and $34(73.9 \%)$ less frequent. When asked about how many times they would have liked to have intercourse 13 women $(35 \cdot 1 \%)$ said that they would have preferred not to have sexual intercourse at all, 13 women $(35 \cdot 1 \%)$ one to four times and 11 women $(29 \cdot 7 \%)$ five to 15 times per month. Ten women were unable to answer. Among the 41 women who had not masturbated during the past month, $13(39 \cdot 4 \%)$ declared that they were not at all interested in sexual intercourse, 11 (33.3\%) wanted to have intercourse one to four times per month and nine $(27 \cdot 3 \%)$ five to 15 (mean 3.3) times.

Among the stimulation techniques effective in producing orgasms caressing of the genitals by the partner was appreciated by most women $(36 ; 76 \%)$, coitus with penile penetration was effective in $18(38.3 \%)$, oral stimulation in $16(34 \%)$, and additional breast caressing and manual masturbation in 12 $(25 \cdot 5 \%)$. A few women enjoyed the use of devices for stimulation - for example, showers and vibrators, rubbing against something, or fantasies and dreams. Enjoyment of the partners' genital caresses was significantly correlated with sufficient lubrication and orgasmic capacity $(p<0.05)$. The partner 
manipulation technique was appreciated significantly more $(p<0.001)$ by the women who had experienced orgasms within the past year. Oral stimulation was enjoyed significantly more $(p<0.01)$ by women with a university education.

\section{CORRELATIONS WITH EDSS SCORES}

Women with lower scores in EDSS reported more significant negative sexual changes regarding lubrication $(p<0.01)$ and the disappearance of clitoral erections $(p<0.05)$. Experiences of decrease in orgasmic capacity were also more common in the lower score group as well as clear changes in orgasmic sensations. The EDSS groups were similar in their statements on contentment as regards sexual experiences as a whole $(84 \%$ and $81 \cdot 8 \%$ ), attractiveness of their bodies $(60 \%$ and $50 \%$ ) and pleasure from their bodies $(73.9 \%$ and $75 \%)$.

\section{EVALUATION OF SEXUAL INTERVIEW}

Forty four women (94\%) had never been asked before to discuss their sexuality in connection with their disease. Thirty nine women $(83 \%)$ considered the interview to be a positive experience. One woman found the interview to be mostly a negative experience and seven women $(15 \%)$ expressed indifference to the whole thing.

\section{ENDOCRINOLOGICAL FINDINGS}

At the time of the interview 16 women (median age 53 years) were no longer menstruating. Menstruation or oestrogen replacement therapy was correlated both with lubrication and to orgasmic sensations. Age had a stronger influence than menstruation.

\section{Discussion}

This is a descriptive and retrospective study of a selected group of severely affected women. The question concerning the recall of sexual experiences from far back in comparison with sexual impressions of today is crucial. There have been a number of validity studies on agreement between questionnaire data and medical records. Harlow and Linet ${ }^{11}$ found that the recall of oral contraceptive use as well as reproductive events, menstrual history, pregnancy history, and childbirth was quite accurate.

Lilius et $a l^{3}$ did not use assessment scales such as the EDSS, but the neurological characterisation of their patients seems similar to that of the patients in the present study. The patients in our study had greater needs of handicap aids $(85 \%)$, however, a fact that probably shows that our patients were more severely afflicted by the disease than those of Lilius et al. ${ }^{3}$ Minderhoud and collaborators examined only less handicapped patients. They described the symptoms as moderate or severe in $40 \%$ to $80 \%$ of the cases, compared with $60 \%$ to $90 \%$ in our study. Lilius et $a l^{3}$ point out the high risk of divorce in patients with a very poor physical condition. This high risk among the more disabled women is also evident from our study. The results of our study concerning loss of sexual interest are much the same $(59.6 \%)$ as in previous studies. The problems of lubrication were greater $(36.2 \%)$ and the orgasmic problems were less frequent $(38 \cdot 3 \%)$. When the women who had never had an orgasm were added to this figure, the sum was greater than $50 \%$, which is similar to the figures of Minderhoud et al. ${ }^{4}$

Weakness of the pelvic floor and also bladder and bowel dysfunction correlated with changes in lubrication as well as in orgasmic capacity. The finding that sexual disorders were correlated with neurological symptoms such as bladder and bowel dysfunction is in accord with earlier results ${ }^{89}$ and shows that the same parts of the autonomic nervous system are responsible for all these functions. When a woman had sensory disturbances in her genitals, manual stimulation by her partner seemed to be more effective than oral stimulation, and the oral stimulation technique was more effective than coital stimulation in producing an orgasm. The experience of lost effects of sexual stimulation techniques could be an informative sign of a decrease in sexual sensory nervous function. The conclusion drawn by Minderhoud et $\mathrm{al}^{4}$ from factor analyses that motor disturbances are of major importance for sexual dysfunction could not be verified in the present study, but the importance of sensory disturbances, weakness of the pelvic floor, and EDSS is supported by our results. Menstruation or oestrogen replacement therapy were correlated with lubrication and to orgasmic sensations, but the age factor had a stronger influence than menstruation on sexual function. Amenorrhoea was slightly more common in the less disabled group of women.

In the present study overall negative sexual changes were significantly more often reported by women with lower scores in EDSS. The women with lower scores had been more aware of their clitoral erections. Among the women with lower scores, a higher number masturbated and had sexual intercourse compared with the situation before the disease. More of them had experienced an orgasm within the past year and a greater proportion lived with a sexual partner compared with the higher score group. Also, there was a higher employment rate in the lower score group.

This study did not include matched controls from the general population. Unfortunately it is not possible to compare our data with those from national survey studies such as the Kinsey or Janus reports as these types of studies include no or very few questions about sexual dysfunction in women. Only in one previous multiple sclerosis study $^{9}$ was a control group used; 25 women with mild multiple sclerosis were matched for parity and age with 25 women with migraine. Only three controls reported some sexual problems or changes in their sexual life during the past year. One of them had 
experienced a sudden loss of libido, another complained of slight dyspareunia, and the third had migraine attacks that were provoked by sexual intercourse.

1 Lundberg PO. Sexual dysfunction in patients with neurological disorders. Annual Review Sex Research 1992;3. logical $121-50$.

2 Lundberg PO, Brattberg A. Sexual dysfunction in selected neurologic disorders: hypothalamo-pituitary disorders, epilepsy, myelopathies, polyneuropathies and sacra nerve lesions. Semin Neurol 1992;12:115-9.

3 Lilius HG, Valtonen EJ, Wikström J. Sexual problems in patients suffering from multiple sclerosis. Scand $\mathcal{F}$ Soc Med 1976;4:41-4.
4 Minderhoud JM, Leemhuis JG, Kremer J, Laban E, Smits PML. Sexual disturbances arising from multiple sclerosis. Acta Neurol Scand 1984;70:299-306.

5 Schneider E. Störungen der Sexualfunktion bei nichttraumatischen Rückenmarkserkrankungen. Fortschr Neurol Psychiatr 1974;42:562-76.

6 Szasz G, Paty D, Lawton-Speert S, Eisen K. A sexual functioning scale in multiple sclerosis. Acta Neurol Scand 1984;70(suppl):37-43.

7 Stenager E, Nylev Stenager E, Jensen K. Sexual aspects of multiple sclerosis. Semin Neurol 1992;12:120-4.

8 Lundberg PO. Sexual dysfunction in patients with multiple sclerosis. Sexuality and Disability 1978;1:218-22.

9 Lundberg PO. Sexual dysfunction in female patients with multiple sclerosis. International Rehabilitation Medicine multiple scle

10 Kurtzke JF. Rating neurological impairment in multiple sclerosis: an expanded disability status scale (EDSS) Neurology 1983;33:1444-52.

11 Harlow SD, Linet MS. Agreement between questionnaire data and medical records. The evidence for accuracy of recall. Am $\mathcal{F}$ Epidemiol 1989;129:233.

\section{NEUROLOGY IN LITERATURE}

\section{Catalepsy}

Catalepsy received considerable attention from Victorian authors. Sherlock Holmes also encountered the phenomenon, although exactly what the phenomenon is would be difficult to say from these extracts, apart from the descriptions of Poe and Eliot. Contemporary medical texts display a similar confusion. Some, like Grainger Stewart, seem to regard the phenomenon as being synonymous with catatonia Stewart states that "prolonged rigidity of muscles characterises catalepsy." The description used by Wilks approaches that of Poe, though with the comment that "If a limb be placed in any position there it will remain." Gowers regarded the phenomenon, in most cases, as hysterical. He describes attacks lasting minutes or hours in which the temperature is lowered, respiration and the heart's actions weakened, and the countenance expressionless. He adds, however, that after an initial phase of muscle rigidity, the limbs remain in any position in which they are placed. ${ }^{3}$ While recognising that the condition was probably not homogeneous, Gowers developed an elaborate hypothesis as to its pathophysiology. Kinnier Wilson defined catalepsy as a state of sustained motionlessness with or without clouding of the sensorium. ${ }^{4} \mathrm{His}$ conclusion that such states were generally hysterica would be one that most modern neurologists, I suspect, would share.

Edgar Allan Poe, 1839, The fall of the House of Usher The disease which had thus entombed the lady in the maturity of youth had left as usual in all maladies of a strictly cateleptical character, the mockery of a faint blush upon the bosom and the face, and that suspiciously lingering smile upon the lip which is so terrible in death.

Edgar Allan Poe, 1844, The premature burial For several years I have been subject to attacks of the singular disorder which physicians have agreed to term catalepsy, in default of a more definitive title. Although both the immediate and the predisposing causes, and even the actual diagnosis of this disease are still mysterious, its obvious and apparent character is sufficiently well understood. Its variations seem to be chiefly of degree. Sometimes the patient lies for a day only, or even for a shorter period in a species of exaggerated lethargy. $\mathrm{He}$ is senseless and externally motionless; but the pulsation of the heart is still faintly perceptible; some traces of warmth remain; a slight colour lingers within the centre of the cheek; and upon application of a mirror to the lips, we can detect a torpid, unequal, and vacillating action of the lungs. Then again the duration of the trance is for weekseven for months; while the closest scrutiny, and the most rigorous medical tests, fail to establish any material distinction between the state of the sufferer and what we conceive of absolute death.

Gustave Flaubert, 1857, Madame Bovary

He remembered hearing about catalepsy, and the wonders of magnetism. He told himself that if only he willed it strongly enough he might succeed in bringing her back to life.

Charles Dickens, 1859, A tale of two cities

As a promising way of setting them right, half of the half-dozen had become members of a fantastic sect of convulsionists, and were even then considering within themselves whether they should foam, rage, roar, and turn cataleptic on the spot. . .

George Eliot, 1861, Silas Marner

... He saw that Marner's eyes were set like a dead man's, and he spoke to him, and shook him, and his limbs were stiff, and his hands clutched the bag as if they'd been made of iron; . . . and a peculiar interest had been centred in him ever since he had fallen, at a prayer-meeting, into a mysterious rigidity and suspension of consciousness, which, lasting for an hour or more, had been mistaken for death.

Wilkie Collins, 1883, Heart and science

"You need be under no anxiety about that," said Benjulia. "I have left orders that Mrs Gallilee is not to be admitted. There is a serious necessity for keeping her out. In these cases of partial catalepsy, there is no saying when the change may come."

Arnold Bennett, 1918, The pretty lady

Leaving a small ring of gas alight in the gas stove, she sat down all dirty on a hard chair in front of it and fell into a luxurious catalepsy.

G D PERKIN Regional Neurosciences Centr Charing Cross Hospital, Fulham Palace Road London W6 8RF, UK

1 Grainger Stewart T. An introduction to the study of the diseases of the nervous system. Edinburgh: Bell and Bradfute, 1884 .

Wilks $S$. Lectures on diseases of the nervous system. London: $\mathrm{J}$ and $\mathrm{A}$ Churchill, 1878.

3 Gowers WR. A manual of diseases of the nervous system. 2nd ed. London: J and A Churchill, 1893.

4 Kinnier Wilson SA. In: Ninian Bruce A, ed. Neurology London: Edward Arnold, 1940. 